\title{
Strategic and tactical use of a community based regional seismic monitoring system
}

\author{
M.R. Hudyma School of Engineering, Laurentian University, Canada
}

J. Wesseloo Australian Centre for Geomechanics, The University of Western Australia, Australia

\section{Abstract}

The Australian Centre for Geomechanics (ACG) has developed a simple, but effective, regional seismic monitoring system that has a number of strategic and tactical applications for monitoring seismicity in mines. From a strategic perspective, installation of a regional seismic sensor is a means of evaluating the severity of a local seismicity problem. This can help decide if a full-blown in-mine microseismic monitoring system is required. From a tactical perspective, a regional seismic sensor can provide a series of operational benefits, including: blast vibration monitoring, blast diagnostics monitoring, identifying events within mine blasts, monitoring of near-mine seismic events, and as backup for an in-mine microseismic system. The versatility of stand-alone regional seismic sensors make them useful tools for mines that do not have a seismic monitoring system, as well as for mines with established in-mine seismic systems.

\section{$1 \quad$ Regional seismic monitoring}

Regional seismic monitoring systems are commonly installed in areas in which macroseismic events (Magnitude +1 to +3 ) are expected. Common applications include near major civilian infrastructure such as nuclear power facilities, as well as near surface water reservoirs (dams). However, there are strategic and tactical benefits to installing a regional seismic monitoring system near mines.

\section{Strategic application - evaluating the severity of a seismic problem}

The decision to install a microseismic monitoring system in a mine cannot be taken lightly. Past experience has found that the installed capital cost of a microseismic system is about AU\$10,000 per channel (Hudyma and Brummer, 2007). A modest system for an average sized mine could require 24-36 channels, giving a capital cost of at least AU\$240,000 to AU\$360,000. In addition, the yearly operating cost for running and maintaining a microseismic system is usually $20-40 \%$ of the original capital cost (Hudyma and Brummer, 2007). For some mines, the need for a microseismic system may be uncertain. A survey of seismically active mines (Hudyma, 2004) identified the factors that contribute to a potential mine seismicity problem, including:

- mine extraction and stoping at significant depth

- high pre-mining stresses

- stress-raising geological features such as stiff dykes and mine-wide faults

- high levels of mine extraction

- rock noise and seismic events reported in the mine, particularly following significant mine blasts.

On an individual mine site basis, other important factors may include:

- nearby mines in similar geomechanical and mining environments may have microseismic systems

- significant groundfalls may have occurred in the mine 
- the desire by mine technical staff to be proactive with regards to risk management.

While each of these factors may be important in helping determine the need for a mine-wide microseismic system, perhaps the best indicator of the need for a microseismic monitoring system is the measurement of the frequency and size of seismic events occurring at the mine. Experience has show that if a regional seismic sensor is located in a low vibration location, relatively high sensitivity can be achieved. Events near magnitude +1 can be reliably identified. The mine blasts each day give an indication of the sensitivity of the regional seismic sensor for detecting seismic events. Table 1 gives an approximate magnitude for various types of mine blasts.

Table 1 Various mine blasts and the equivalent event size recorded on a regional seismic sensor

\begin{tabular}{lr}
\hline Blast Type & Richter Magnitude \\
\hline Secondary blasts or single development holes & 0 \\
Development face or drop raise blast & +0.5 \\
Small stope blast & +1.0 to +1.5 \\
Large stope blast & +1.5 to +2.0 \\
\hline
\end{tabular}

A small array of surface seismic sensors can be quickly and inexpensively deployed to determine the severity of a seismicity problem in a mine. For example, one year of data collected in a Canadian mine is shown in Figure 1. There are 2 regional seismic sensors within about five kilometres of the mine. Important observations from this year of data include:

- There are 79 mine production blasts recorded in the year, with recorded blasts sizes varying from as small as magnitude +1.2 to a maximum of magnitude +2.0 .

- There have only been three seismic events recorded during the 12 month period, two events with a magnitude of +1.2 and one event with a magnitude of +1.3 .

- Blasts and events smaller than magnitude +1.2 are not recorded by the regional seismic sensors at this mine.

The argument could potentially be made that the need for a full mine-wide microseismic system may not be warranted. Certainly, the regional seismic system has not collected data that shows a severe seismic problem.

In a separate example, 10 months of data has been collected by three regional seismic sensors near a Canadian mine. A time history of the event magnitudes is shown in Figure 2.

In this case study:

- There are 166 mine blasts recorded in the 10 months, with recorded blast sizes varying from as small as magnitude +0.5 to a maximum of magnitude +1.9 .

- There have been 13 seismic events recorded during the 10 month period, with magnitudes varying from +0.7 to a maximum magnitude of +2.2 .

- Blasts and events smaller than magnitude +0.5 are not recorded by the regional seismic sensors at this mine.

In this example, the seismic array is more sensitive and has recorded several events smaller than magnitude +1.0. A more compelling case for a mine-wide microseismic system could be made, largely because two mining induced seismic events of magnitude +2 have been recorded. 


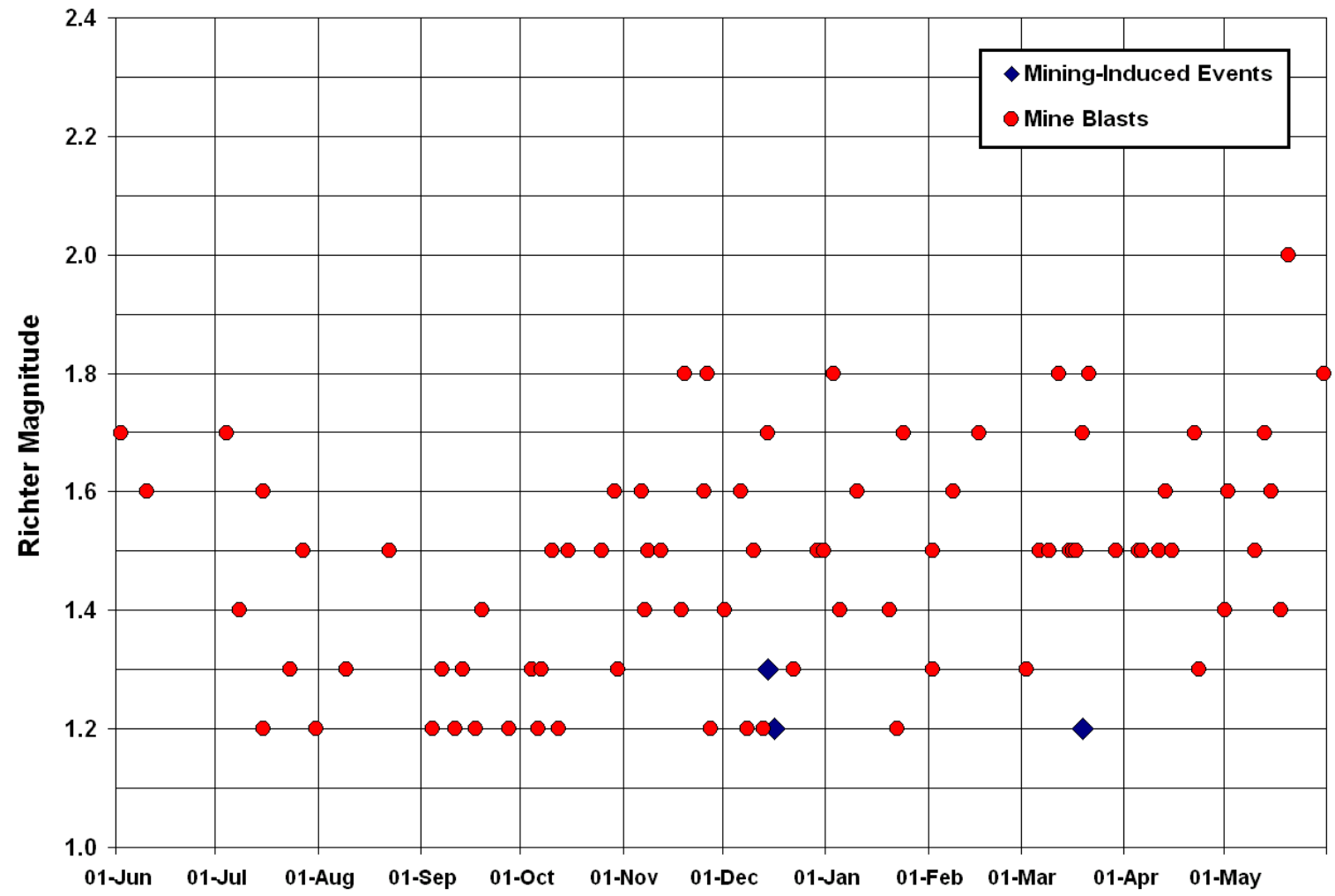

Figure 1 One year of mine blasts and mining induced seismic events collected using two regional seismic sensors near a Canadian mine

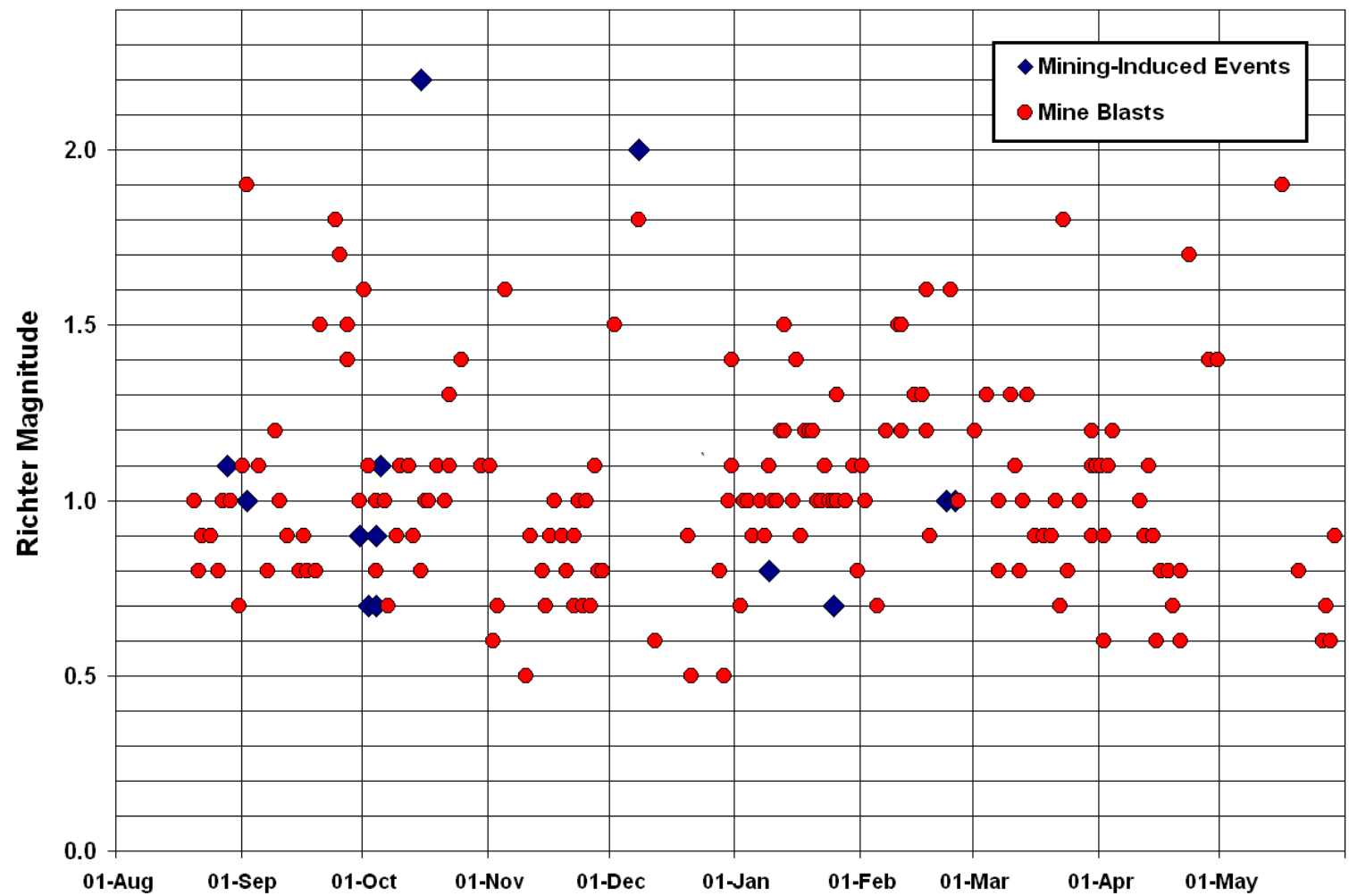

Figure 2 Ten months of mine blasts and mining induced seismic events collected using three regional seismic sensors near a Canadian mine 


\section{Tactical applications}

Regional seismic sensors can provide a number of supplementary technical benefits.

\section{1 Blast vibration and blast diagnostics monitoring}

The sensor can be used to measure blast vibrations for statutory vibration monitoring. Mines located near populated areas are often required to monitor vibrations from all mine blasts. This can be adequately achieved with a regional seismic sensor, giving a maximum vibration (peak particle velocity) for each blast.

If the sensor is located within several hundred metres of a mine blast, the regional seismic sensor can also be used for blast diagnostics monitoring. Each delay of a mine blast can often be identified. The regional seismic sensor can determine if the blast delays went off as planned. In addition, the data will show the delays with the highest vibrations. Figure 3 is an example of a development round recorded by a regional seismic sensor, at a distance of about $600 \mathrm{~m}$. Each of the development delays can be identified. Figure 4 is an example of the vibrations recorded for a mine production blast. Each of the production blast delays can be identified.

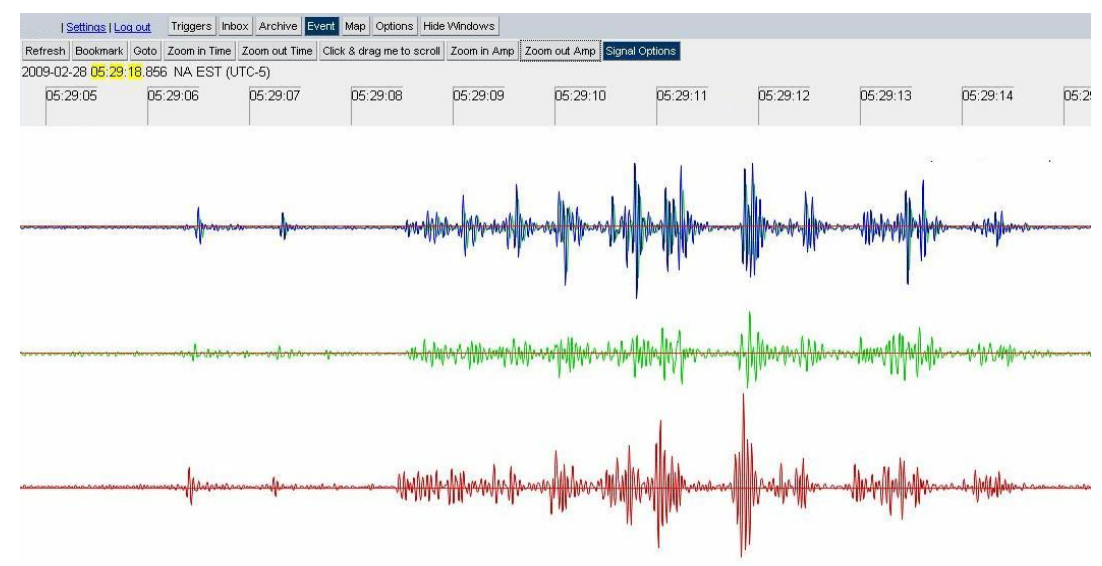

Figure 3 Vibrations from an eight second long development round recorded by a regional seismic sensor

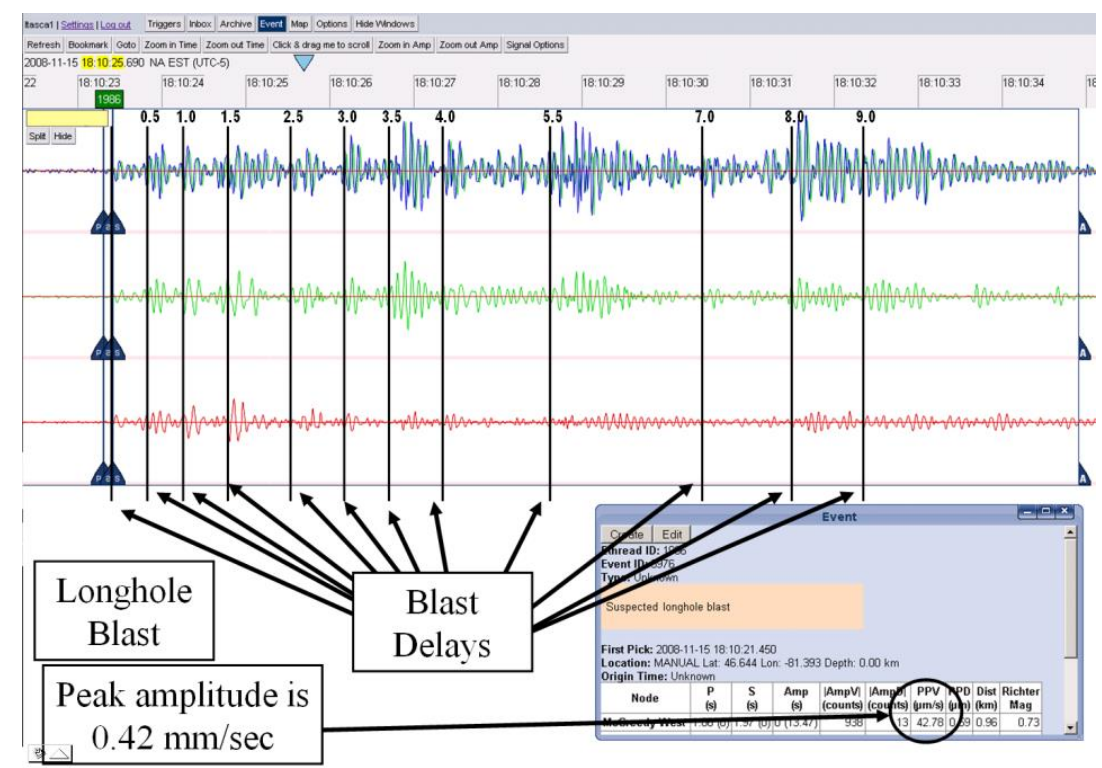

Figure 4 Delays of a production blast can be clearly identified by a regional seismic sensor at a distance of several hundred metres. The peak amplitude (peak particle velocity) of the blast is also shown 


\section{2 Detecting events within blasts and complex events}

Most mines use a central blast time. During this time, the in-mine microseismic system sees each of the blast delays, often triggering the seismic system ten or more times. The data collect by the in-mine system is often incomplete or corrupted by the complexity of the mine blast. If a large seismic event occurs within the blast, often it cannot be identified and a magnitude of the event cannot be assessed.

A regional seismic system gives a full and continuous trace of the vibrations within the blast. If a large seismic event occurs, it will be visible within the regional seismic sensor data. Figure 5 is an example of a large event within a blast, recorded by two different regional seismic sensors.

Figure 6 shows an example of a complex mining induced event, with two magnitude +1.3 events occurring within one second of each other.

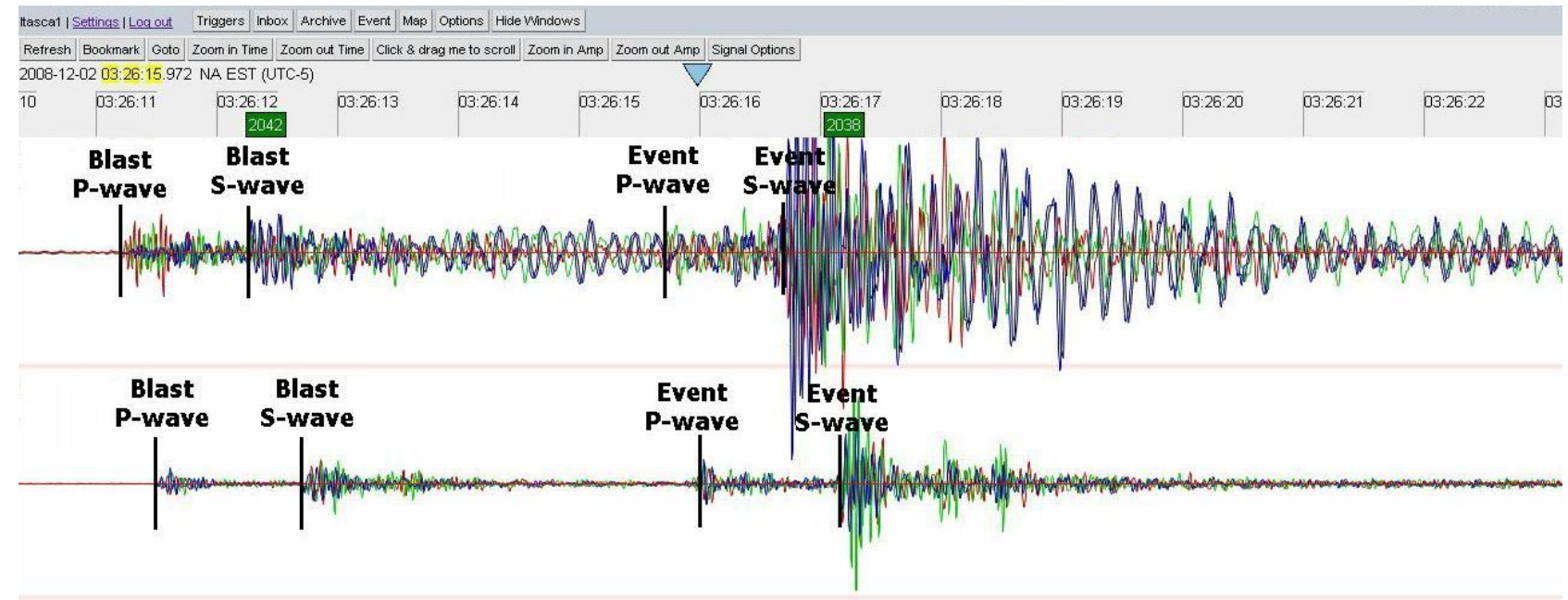

Figure 5 A mine blast is recorded by two regional seismic sensors, followed by a mining induced seismic event about four seconds after the start of the mine blast
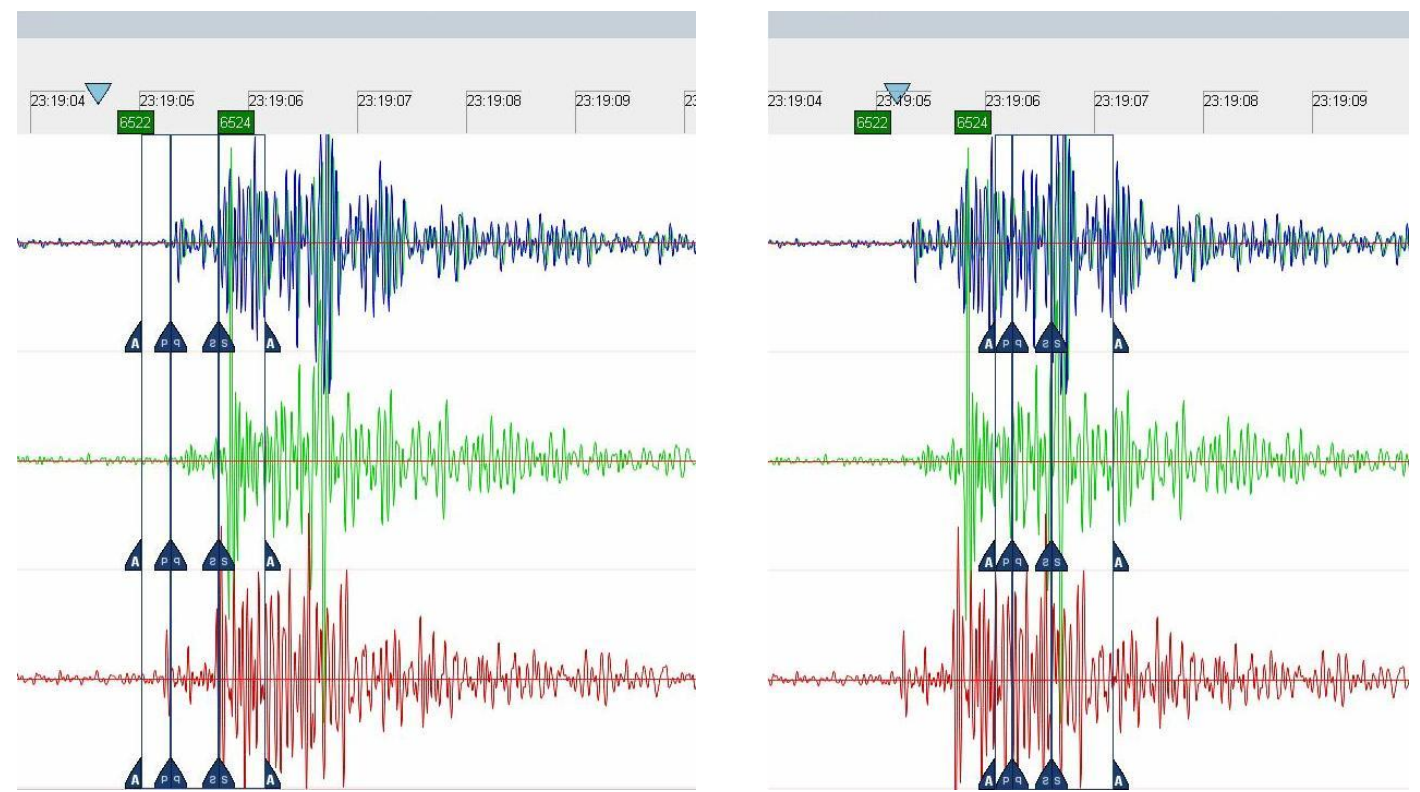

Figure 6 A complex mining induced event, with two magnitude +1.3 events occurring within about one second of each other. The $p$-wave and $s$-wave phases are identified for each of the events in the two figures 


\section{3 Monitoring near mine events}

Some mines have reported that large seismic events have occurred near the mine, but not within the mine. These 'near mine events' are often of a considerable magnitude, and are often reported by people near the mine. The in-mine microseismic systems are designed to identify and locate seismic events within the mine, however, they may not be reliable for detecting 'near-mine' events. The continuous data trace of regional seismic sensors may be beneficial in identifying 'near-mine' events and assessing an event magnitude.

\section{4 Evaluating the largest potential seismic event}

Three months of seismic events and blasts recorded by an array of three regional seismic sensors are shown on a time history of event magnitude in Figure 7. The regional seismic data shows a number of important pieces of information:

- There are 159 blasts in three months, with blast sizes varying from as small as +0.0 to a maximum of +1.7 .

- There are 89 mining induced seismic events in three months, with magnitudes varying from as small as Richter magnitude +0.2 to a maximum of +2.2 , including four events with a magnitude +2.0 or greater.

- This gives an average return time of a magnitude +2.0 event of about 22 days.

- The mine blasts occur almost every shift (a cut and fill mine), however, the mining induced seismic events do not follow a similarly consistent pattern. There are time periods in which the frequency of larger events is higher. This can likely be related to the location of mine blasts preceding the events.

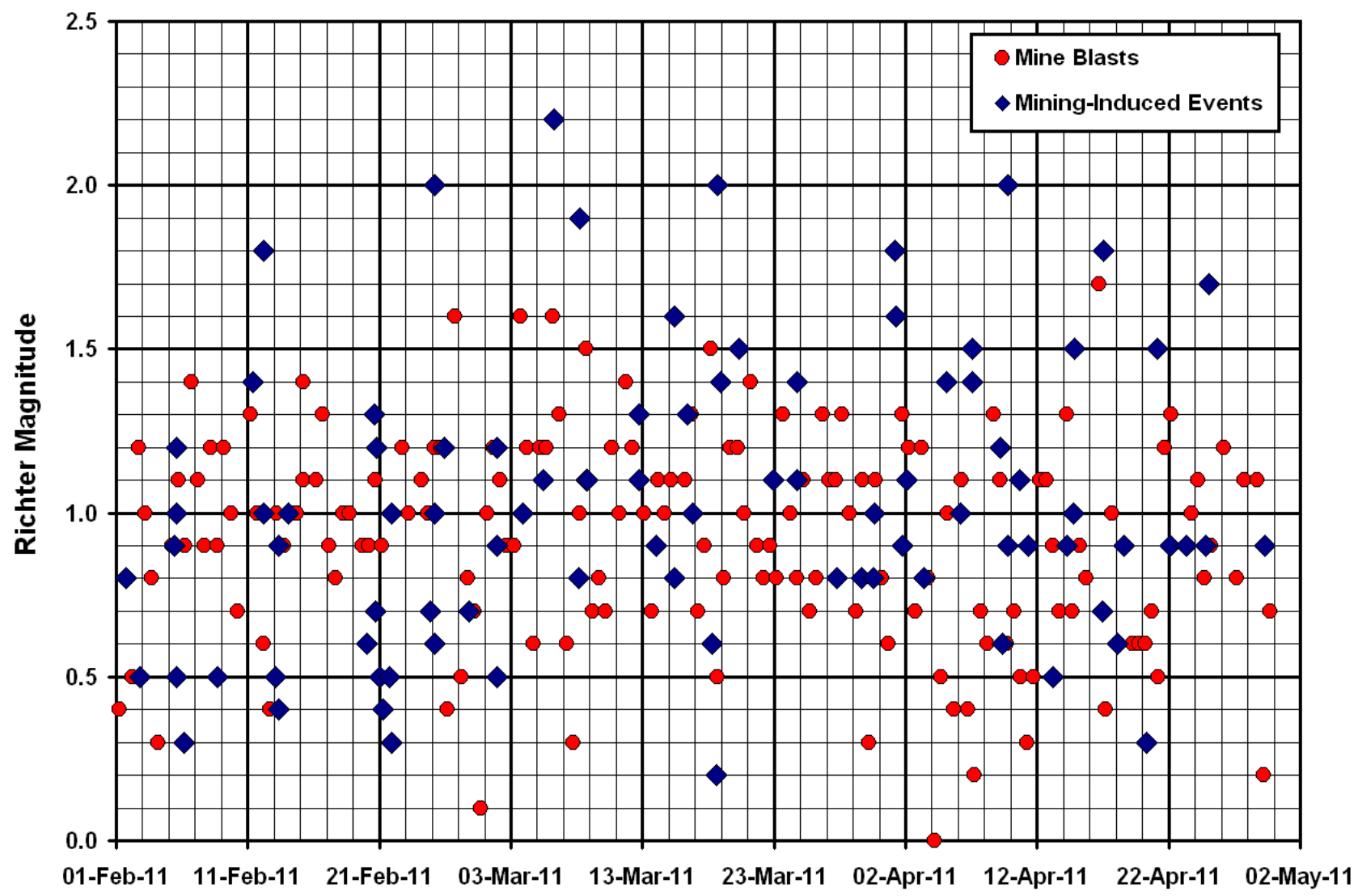

Figure 7 Three months of seismic events and blasts recorded by an array of three regional seismic stations near a seismically active mine 
Many microseismic monitoring systems cannot record reliable magnitudes for large events, hence the severity of the problem is uncertain. For a significant population of events, there is a relation between the frequency of occurrence of the events and the magnitude of the events (Gutenberg and Richter, 1944). This is called the Gutenberg-Richter frequency-magnitude relation. The frequency-magnitude relation for the seismic events in Figure 7 is shown in Figure 8. This chart contains a number of important pieces of information:

- The data for the case study is shown with the triangles, while a best-fit to the data is shown with the dashed line. The best-fit matches the data well, suggesting that the data is good quality and that the magnitude scale is well-behaved (reliable).

- The equation of the slope of the best-fit should follow the form:

$$
\log _{10} \text { (Number of events) }=a-b * m
$$

where:

a $=$ a constant representing the seismic activity rate.

$\mathrm{b}=\mathrm{a}$ constant representing the relative frequency of large versus small events.

$\mathrm{m} \quad=\quad$ event magnitude.

- The slope of the best-fit of the data in Figure 8 is 1.0, which is the expected value. This again suggests that the data is well-behaved.

- At magnitude +0.9 , there is a deviation between the recorded seismic data and the best-fit line. This is the sensitivity of the regional seismic array, so the regional array should be able to reliably detect all events greater than magnitude +0.9 , but for less than magnitude +0.9 , not all of the mining induced events are recorded.

- The expected largest event for a large population of good quality data is approximately equal to $(a / b)$. For this example, $(a / b)$ is about magnitude +2.6 .

- The activity rate (a) for the three month period is about 2.7. For a 12 month period, (a) would be approximately 3.3. This gives an expected largest event, on a yearly basis, of magnitude +3.3 .

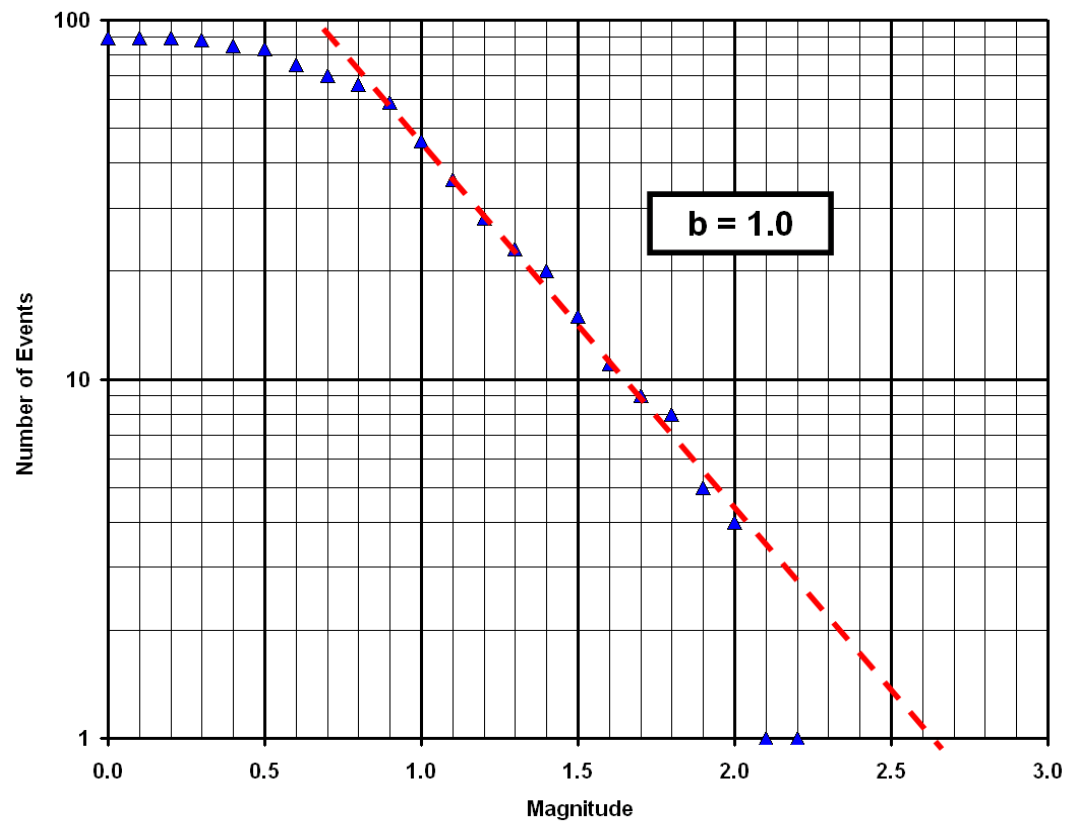

Figure 8 Gutenberg-Richter frequency-magnitude relation for the events in Figure 7 
With the reliable magnitude scale provided by the regional seismic array, a quantitative assessment of the largest expected event on a yearly basis can be estimated.

\section{5 Backup seismic monitoring system}

An obvious, but important role of regional seismic systems is to provide an alternative means of seismic monitoring, during periods of downtime for a mine-wide microseismic system. While a regional seismic system does not provide useful source location or the same degree of sensitivity as a microseismic system, it will show if a substantial seismic event has occurred while the microseismic system was down.

\section{6 Monitoring the seismic gap}

The example previous shows the ability to use seismic data to evaluate the largest expected event. For many microseismic systems, events larger than magnitude +1 are not recorded with a reliable magnitude. Regional earthquake monitoring systems operated by government services often do not detect events smaller than about magnitude +2.5 . As a result, there is a magnitude range between magnitude +1 and magnitude +2.5 in which events may not be recorded with accurate magnitudes. This 'gap' in the seismic record has been noted in the data of several mining operations.

A regional seismic monitoring array bridges the gap between in-mine microseismic systems and the government earthquake monitoring systems.

\section{$4 \quad$ Regional seismic sensor layout}

\section{1 Monitoring philosophy}

In most cases, regional seismic sensors are located in very low noise locations, and high quality sensors and monitoring hardware are utilised. Frequently, the sensors are located at a significant distance from mine workings, to minimise background noise. Running power and communications to the remote location, or using radio telemetry and solar power, adds extra cost to the station.

The ACG regional system follows a different philosophy. In this case, low vibration locations are sought, but locations near the mine that are intermittently noisy may also be used. To compensate for the fact that there are intermittent noisy periods, usually two to four sensors are installed. While one sensor may have a temporarily high level of background noise, this is very unlikely to occur concurrently for all of the sensors. Experience has shown that having a combination of one sensor at a remote location underground in the mine, along with one or two surface sensors provides a high dynamic range for a regional seismic array.

\section{2 Lessons learned}

Experience has shown that surface sensors are easier to install and maintain compared to underground sensors. The surface sensors may be more likely to be subject to temporary cultural noises, but this is usually accounted for by installing more than one surface sensor.

Underground sensors will often have a lower noise background, but may be subject to raypath effects if the sensors are too close to mine development, stopes or large voids. The key is to pick remote locations in the mine, or areas that are distant from the current workings and distant from associated mine cultural noises (drills, mobile equipment, ventilation fans, and orepasses).

Placing the sensor directly on bedrock will give a preferable signal, however, on surface this is sometimes not possible if a convenient, low vibration bedrock location is not available. Placing the sensor on a concrete slab or foundation will have a higher background noise, and may be subject to resonance in the foundation. Despite the higher background noise and potential for resonance, placing the sensor on a concrete slab or foundation surface often gives adequate results. There is also no need to mount or grout the sensor within a borehole. 


\section{$5 \quad$ Summary and conclusions}

Regional seismic monitoring stations can provide both strategic and tactical benefits to a mining operation. The regional seismic arrays developed by the Australian Centre for Geomechanics have the benefit of being low cost and flexible in their installation. Arrays of sensors have been established in a number of mining districts, including: Kalgoorlie-Kambalda, Leinster, Beaconsfield, and Broken Hill in Australia, and near Sudbury, Kirkland Lake and Rouyn in Canada.

\section{Acknow l edgements}

The authors wish to acknowledge the sponsors of Phase 3 of the Mine Seismicity and Rockburst Risk Management (MSRRM) Project and the Canadian Mining Industry Research Organization (CAMIRO) for financial support in the development and application of regional and seismic monitoring systems in Australia and Canada.

The authors would like to sincerely thank the following sponsoring companies Phase 3 of the MSRRM project: Minerals and Energy Research Institute of Western Australia (MERIWA), Barrick Gold of Australia, Noilsk Nickel (formerly LionOre Australia Ltd), BHP Billiton Nickel West, Perilya Limited, Lightning Nickel (Independence Group NL), LKAB Sweden, Kirkland Lake Gold, Agnico-Eagle Mines Ltd, Kalgoorlie Consolidated Gold Mines, Allstate Explorations NL (Beaconsfield Gold NL), Newcrest Cadia Valley Operations (Ridgeway), Harmony Mt Magnet Gold, Xstrata Copper (Kidd Mine), Oxiana Limited (Golden Grove), Newmont Asia Pacific, AngloGold Ashanti Australia, Codelco Chile (El Teniente), Xstrata Zinc (Brunswick Mining and Smelting), Reliance Nickel P/L (Consolidated Minerals Group), Xstrata Nickel (Cosmos Nickel Project - Sir Samuel Mines) and Gold Fields Australia (St Ives Gold and Agnew Gold).

\section{References}

Gutenberg, B. and Richter, C.F. (1944) Frequency of earthquakes in California, Bulletin of the Seismological Society of America, Vol. 34, pp. 185-188.

Hudyma, M.R. (2004) Mining induced seismicity in underground, mechanised, hardrock mines - Results of a world wide survey, Australian Centre for Geomechanics Research Report, 138 p.

Hudyma, M.R. and Brummer, R.K. (2007) Seismic Monitoring in Mines - Design, Operation, Tricks and Traps, in Proceedings from the 1st Canada-U.S. Rock Mechanics Symposium, Vancouver, pp. 1423-1430. 
